\title{
Knowledge generation for enhancing design creativity through co- creative Virtual Learning Communities
}

\author{
Carlos García-García ${ }^{\mathrm{a}}$, Vicente Chulvi ${ }^{\mathrm{b}}{ }_{*}$, Marta Royo $^{\mathrm{c}}$ \\ ${ }^{a}$ Universitat Jaume I, Dep. d’Enginyeria de Sistemes Industrials i Disseny, Castellón, Spainb \\ bUniversitat Jaume I, Dep. d’Enginyería Mecànica i Construcció, Av. Sos Baynat s/n E-12071, Castellón, Spainc \\ ${ }^{c}$ Universitat Jaume I, Dep. d’Enginyería Mecànica i Construcció, Castellón, Spain
}

\begin{abstract}
With the current technological explosion, the arrival of Web 2.0 and the growth of ICTs, designers' tools can be understood and used by novice users. With this statement in mind, and considering previous works that claim that team-working enhances creativity, the present paper reports on an experiment conducted to test whether a large group of creative people organised in a Virtual Learning Community are able to produce a Graphic Design with a satisfactory level of creativity starting from an almost complete lack of knowledge on the discipline, where a "satisfactory level of creativity" is understood as being that level which can be achieved by an individual with specific knowledge in the subject working in isolation. The results were assessed by means of an adapted questionnaire based on the CPSS taxonomy, and statistically analysed using ANOVA. The conclusions appear to reinforce the idea that virtual team-working enhances creativity, but the lack of specific competence training can be discerned by an expert eye.
\end{abstract}

Keywords: Knowledge generation; Virtual Learning Community; co-creation; creativity; graphic design

\section{Introduction}

As Huerta Vásquez (2012) postulates, the tools that engineers and designers employed up to the present day were complex and required exclusive qualified use. But with the current technological explosion, technology has become more "user-friendly" and so novices are able to use it as well. Thus, it can be said that the new technological trends have helped to democratise creativity and participation in the design process at several levels (Sanders \& Simons, 2009). Sanders and Simons define co-creation as "one act of 
collective creation that is experienced in a joint way by two or more individuals".

Co-creation can occur throughout the different stages of the design process. Nonetheless, the probability of achieving a higher impact is related to the application of co-creation processes in the early stages of the creative process. Sander and Simons (2009) consider co-design or collaborative design as one specific case of co-creation, and they define it as "the collective creativity such as it is applied along all the design process".

The user's perspective changes notably with the new situation created with the arrival of Web 2.0, since, here, all users become information creators, editors, and customers. Along these lines, the research conducted by Adell (2012) defends that previously, with Web 1.0, it was the institutions that were in charge of publishing all kinds of contents. Nonetheless, in Web 2.0 the internet user "contributors" are in charge of publishing the contents of the web. Moreover, the opportunities that Web 2.0 offers users are very varied, and so they can adopt different roles, such as those of creator, editor, critic, spectator or, simply, inactive user. Domingo et al. (2008) emphasise the capacity of Web 2.0 for inspiring a new creative paradigm, and for becoming the new force driving mass creativity, or mass innovation, as it was denominated by Charles Leadbeater (2007).

The authorship of the term "virtual community" is attributed to Howard Rheingold, who defines virtual communities as "social aggregations that emerge from the network when there is an adequate number of people that initiate public discussions during enough time and with the sufficient human emotion to create relational nets of people in the cyberspace" (Rheingold, 1993). Powers (1997) defines them as "one electronic space where a group of people get together usually to exchange ideas, and it also denotes a generalisation of habitual life, in which we can perform a set of activities 
that are additional to the common ones, through computational devices, like meeting, chatting, sharing and collaborating with other people, thereby defining an environment of social relations".

The present work aims to verify the claim that, with the appearance and growth of the ICTs (Information and Communications Technologies), the designer's tools can be understood and used by novices, and these tools, together with those intended for Co-Creation, facilitate the novices' creativity and participation in the design process. With this aim, this paper reports on an experiment conducted to test whether a large group of creative people organised in a Virtual Learning Community (VLC) are able to elaborate a Graphic Design with a satisfactory level of creativity starting from an almost total lack of knowledge about the discipline in which the work is carried out. The advantage of a VLC is that it is able to generate collective knowledge through dialogue and the interconnection of its members in a combination of virtual and face-to-face work and by the use of the social networks to foster communication. By "satisfactory level of creativity" we are referring to the level that can be achieved by an individual with specific knowledge in the subject working in isolation.

It is known, due to previous studies, that creativity is enhanced when working in design groups (Alves et al., 2007; González-Cruz et al., 2008). Nonetheless, the conclusions of the present work will have this fact into account since the hypothesis refers to the increase of creativity through co-creative Virtual Learning Communities regarding to the knowledge generation. So, as the "novice" creative people have no knowledge on the skills and competences needed to perform correctly the Graphic Design with a satisfactory level of creativity, it is assumed that they would not be able to carry on it lonely, but they will be able to achieve this satisfactory level by cogenerating the needed knowledge to perform the task. 


\section{Experimental proposal}

\subsection{Sample}

The sample for the experiment was composed of university students. The objective was to create two different groups. For the "individual with knowledge" work mode, 11 students from the third year of the Degree in Design Engineering were selected at random. Ages ranged from 21 to 32 years old. For the "virtual teams without knowledge" work mode, the students were selected from the third year of the Degree in Primary School Education specialized in Physical Education. Since the samples to be compared are the results of the design process, the second group must provide 11 designs, and so 11 teams were needed. The number of volunteers for this sample was 86 students, with ages between 21 and 40 years old (there were more younger than older). The 86 students were then randomly divided into 11 teams of 6 to 9 individuals each. As all of them are in the same degree course -third year-, it is possible that some of them had worked together previously in the first or second year of the Degree studies. So this is a variable that the research team was not able to control.

In order to ensure that the students of the second group had no previous knowledge about the discipline in which the work is carried out, they were shortly interviewed about these four points:

1) Students where asked if they know the use of professional design tools. Only one of the 86 students have basic knowledge in one tool (Photoshop).

2) They were shown a video of an advertising campaign (Visa, "Life flows faster" by Saatchi \& Saatchi) and they were asked to analyse the elements of visual language used to communicate the idea. None of them were able to provide with 
a satisfactory answer.

3) They were asked if they feel capable of carry out individually a creative project of graphic design for communicating and idea. 37\% answer YES, 30\% answer NO, and the remaining $37 \%$ of the students answer that they are "not sure".

4) They were asked if they feel capable of carry out in teams a creative project of graphic design for communicating and idea. In this case, $62 \%$ answer YES, $14 \%$ answer NO, and the remaining $24 \%$ of the students answer that they are "not sure".

\subsection{Development}

In the case of group A (individual work with knowledge), the students were asked to produce a graphic design in order to commemorate World AIDS Day. The graphic design has to contain a slogan and a logo, and it must transmit a message. It must be presented in A3 format, and all the elements should be original and created by the designer. This stage was carried out in a room with enough computers for each student to have his or her own. They were able to use professional design tools, such as digital cameras, Photoshop, Illustrator, digital sketching, and so forth. They also had materials available to them so that they could produce an initial sketch using manual techniques. They were given 10 weeks, 4 hours' work per week, to complete the graphic design.

In the case of group B (virtual teamwork with no knowledge), the students were asked to produce a graphic design based on an idea from an advertisement created by a professional audiovisual media studio. They were asked to compose a self-discourse in order to come up with a graphic design which conveys the same message. The work mode is based on B-Learning, so face-to-face and virtual work are combined. This allows the creative process to be made more dynamic, and it guarantees homogeneity 
between all of the creative team members as regards their chances of participation and decision-making. At the same time, it also allows for delocalisation of the creative team and asynchronous work without this having a detrimental effect on the creativity of the results. The work was performed over a period of 10 weeks, in which they had to work two hours per week face-to-face, and another two hours per week in a virtual mode, by using the social network Google+ as a communication tool. Inside Google+, the students disposed of Google Hangouts as communication tools, which allows videoconferences with several members, and also group chats. The main aim of using this social network is for it to act as a nerve centre for the project communications. The chosen networks fit the specific needs of the project regarding the profiles or number of members and the context in which the creative activity is carried out, and it can also be complemented by other ICT platforms oriented towards document management. For the face-to-face sessions, the groups had a room with drawing tables and materials at their disposal allowing them to experiment with different graphic-plastic techniques, such as aquarelle, gauche, India ink, wax crayons, collage, and so on. They also had the same professional tools as group A (digital cameras, Photoshop, Illustrator, digital sketching, etc.), but hardly anyone used them due to their lack of knowledge.

The reason of fixing a problem for individual designers while leaving a free topic for inexpert group was motivated because the individual designers had previously the knowledge of how to use the graphic language for building a message. So, they have no problem if they were asked to work in an specific topic, even if they initially don't know about that topic. Therefore, it is assumed that the topic will have no influence in results since there is no need to generate new knowledge. On the other hand, the inexpert teams are initially ignorant of the use of the graphic language. They must generate the collective knowledge about how to use the syntax of the visual language. 
So, it was decided to allow the teams to choose a related topic in which they feel confortable in order to facilitate the knowledge generation in the limited time of the experience. That is, it was pretended that the topic was not an interference and the learning process and creative development could be speed up.

\subsection{Creativity measurement}

An adapted questionnaire based on the Creative Product Semantic Scale (CPSS) taxonomy of Besemer and O'Quin (1989) was used to evaluate creativity. The CPSS analyse the creativity taxonomically by three main branches: novelty, resolution and style. Each branch has several subdivisions which ramify into semantic bi-polar pairs, which are used to elaborate the questionnaires. So, the questionnaire will ask to assess the creativity by asking in different terms and in a random and disorganized way about the main factors that define the creativity. The value of each main factor is calculated as the mean of the bi-polar pairs selected for the assessment, and the creativity as the mean value of the chosen main factors.

The use of adapted questionnaires according to the different studies to be performed has been previously used and defended in several works by different authors (White \& Smith 2001; Kurt 2001; O'Quin 2006; Chulvi et al. 2012). In this work, the dimensions of style and novelty were considered, as shown in Figure 1. The dimension resolution was not considered in this study, because, for the graphic designs analysed, it was considered that all of them are going to achieve the function that they are supposed to, in this case, to convey a message graphically. How well this message is going to be transmitted is considered to be linked to its aesthetics, and this feature is going to be evaluated with the dimension style.

\begin{tabular}{llllllllll}
\hline Boring & O & O & O & O & O & O & O & Interesting
\end{tabular}




\begin{tabular}{|c|c|c|c|c|c|}
\hline Old Hat & $\begin{array}{llll} & 0 & 0 & 0\end{array}$ & $\mathbf{O}$ & $\mathbf{O}$ & & Radical \\
\hline Harmonious & $\begin{array}{llll}0 & 0 & 0 & 0\end{array}$ & $\mathbf{O}$ & $\mathbf{O}$ & $\mathbf{O}$ & Jarring \\
\hline Attractive & $\begin{array}{llll}0 & 0 & 0 & 0\end{array}$ & $\mathbf{O}$ & $\mathbf{O}$ & $\mathbf{O}$ & Unattractive \\
\hline Botched & $\begin{array}{llll}0 & 0 & 0 & 0\end{array}$ & $\mathbf{O}$ & $\mathbf{O}$ & $\mathbf{O}$ & Well-Made \\
\hline Clear & $\begin{array}{llll}0 & 0 & 0 & 0\end{array}$ & $\mathbf{O}$ & $\mathbf{0}$ & $\mathbf{O}$ & Ambiguous \\
\hline Understandable & $\begin{array}{llll}0 & 0 & 0 & 0\end{array}$ & $\mathbf{O}$ & $\mathbf{O}$ & $\mathbf{O}$ & Mysterious \\
\hline Expert & $\begin{array}{llll}0 & 0 & 0 & 0\end{array}$ & $\mathbf{O}$ & $\mathbf{O}$ & $\mathbf{O}$ & Inept \\
\hline Astonishing & $\begin{array}{llll}0 & 0 & 0 & 0\end{array}$ & $\mathbf{O}$ & $\mathbf{O}$ & $\mathbf{O}$ & Commonplace \\
\hline Crude & $\begin{array}{llll}0 & 0 & 0 & 0\end{array}$ & $\mathbf{O}$ & $\mathbf{O}$ & $\mathbf{O}$ & Well-Crafted \\
\hline Incomplete & $\begin{array}{llll}0 & 0 & 0 & 0\end{array}$ & $\mathbf{O}$ & $\mathbf{O}$ & $\mathbf{O}$ & Complete \\
\hline Exciting & $\begin{array}{llll}0 & 0 & 0 & 0\end{array}$ & $\mathbf{O}$ & $\mathbf{O}$ & $\mathbf{O}$ & Dull \\
\hline Warmed Over & $\begin{array}{llll}0 & 0 & 0 & 0\end{array}$ & $\mathbf{O}$ & $\mathbf{O}$ & $\mathbf{O}$ & Trendsetting \\
\hline Ordinary & $\begin{array}{llll}0 & 0 & 0 & 0\end{array}$ & $\mathbf{O}$ & $\mathbf{O}$ & $\mathbf{O}$ & Shocking \\
\hline Organised & $\begin{array}{llll}0 & 0 & 0 & 0\end{array}$ & $\mathbf{O}$ & $\mathbf{O}$ & $\mathbf{O}$ & Disorganised \\
\hline Original & $\begin{array}{llll}0 & 0 & 0 & 0\end{array}$ & $\mathbf{O}$ & $\mathbf{O}$ & $\mathbf{O}$ & Commonplace \\
\hline Ornate & $\begin{array}{llll}0 & 0 & 0 & 0\end{array}$ & $\mathbf{O}$ & $\mathbf{O}$ & $\mathbf{O}$ & Plain \\
\hline Perfect & $\begin{array}{llll}0 & 0 & 0 & 0\end{array}$ & $\mathbf{O}$ & $\mathbf{O}$ & $\mathbf{O}$ & Imperfect \\
\hline Predictable & $\begin{array}{llll}0 & 0 & 0 & 0\end{array}$ & $\mathbf{O}$ & $\mathbf{O}$ & $\mathbf{O}$ & Novel \\
\hline Revolutionary & $\begin{array}{llll}0 & 0 & 0 & 0\end{array}$ & $\mathbf{O}$ & $\mathbf{O}$ & $\mathbf{0}$ & Average \\
\hline Simple & $\begin{array}{llll}0 & 0 & 0 & 0\end{array}$ & $\mathbf{O}$ & $\mathbf{O}$ & $\mathbf{O}$ & Complex \\
\hline Meaningless & $\begin{array}{llll}0 & 0 & 0 & 0\end{array}$ & $\mathbf{O}$ & $\mathbf{O}$ & $\mathbf{O}$ & Meaningful \\
\hline Startling & $\begin{array}{llll}0 & 0 & 0 & 0\end{array}$ & $\mathbf{O}$ & $\mathbf{O}$ & $\mathbf{0}$ & Stale \\
\hline Coarse & $\begin{array}{llll}0 & 0 & 0 & 0\end{array}$ & $\mathbf{O}$ & $\mathbf{O}$ & $\mathbf{O}$ & Elegant \\
\hline
\end{tabular}

Figure 1. Questionnaire used in the experiment, based on CPSS

The questionnaire was answered by 10 evaluators. Four of them were Design

Engineering lecturers specialised in Graphic Design, another four were Design

Engineering lecturers but not specialised in Graphic Design, and the remaining two had 
no experience in Design Engineering. This mixture of expert and non-expert evaluators was done in accordance with the claim by Besemer and O'Quin (1989) that CPSS was developed with the intention of being usable by non-expert raters.

\section{Results}

The individual work of the 11 individuals with knowledge (group A) yielded the graphic designs shown in Figure 2. The 11 graphic designs developed in the virtual work by the teams with no knowledge (group B) are shown in Figure 3.
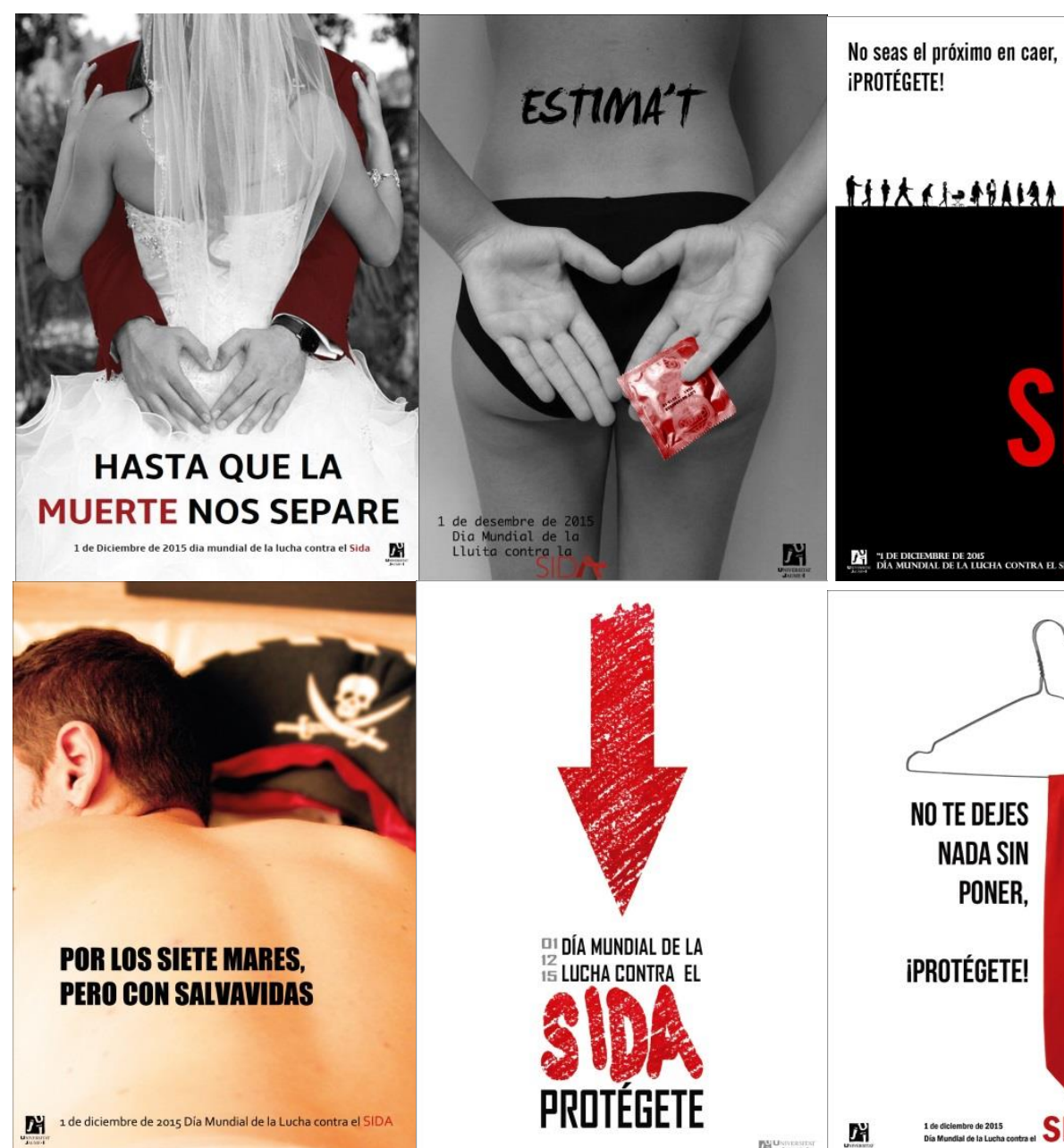

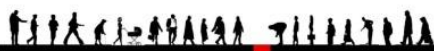
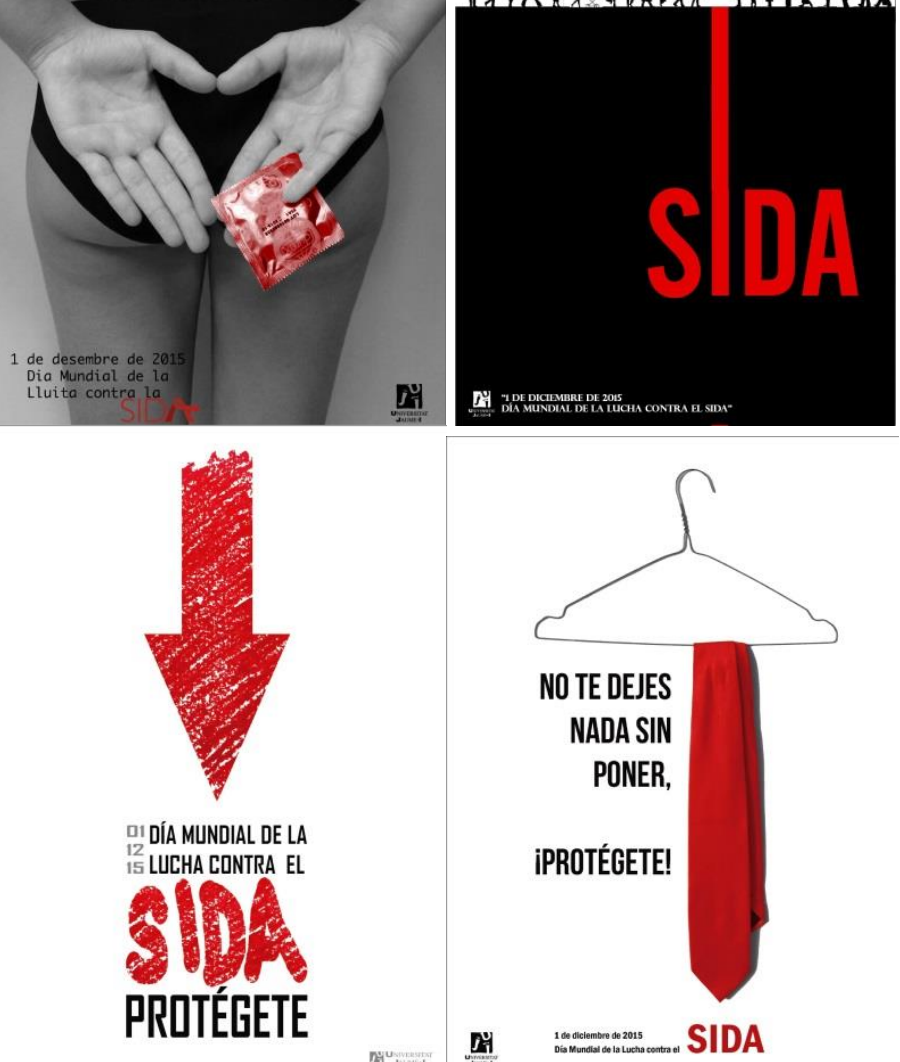


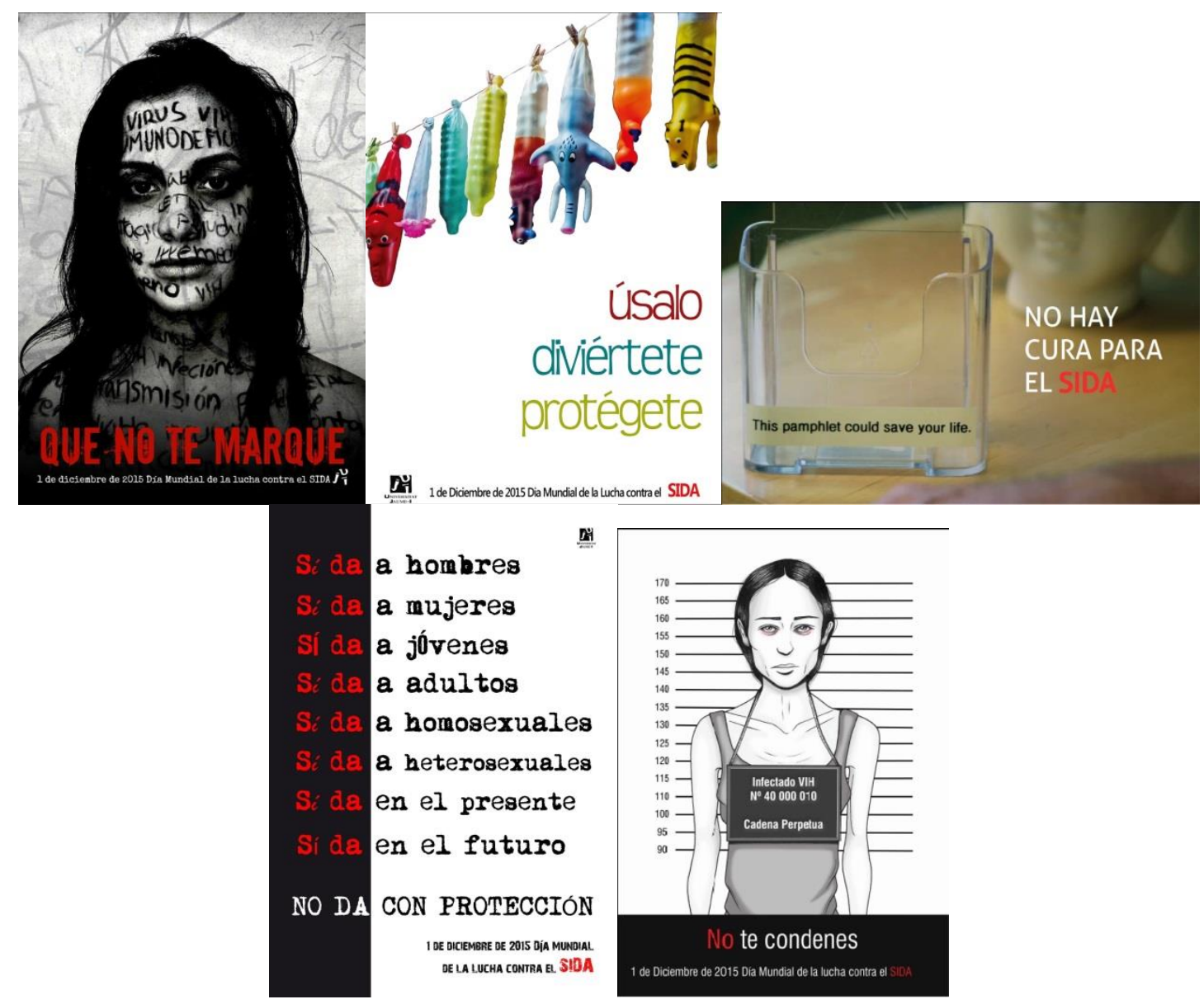

Figure 2. Designs from group A

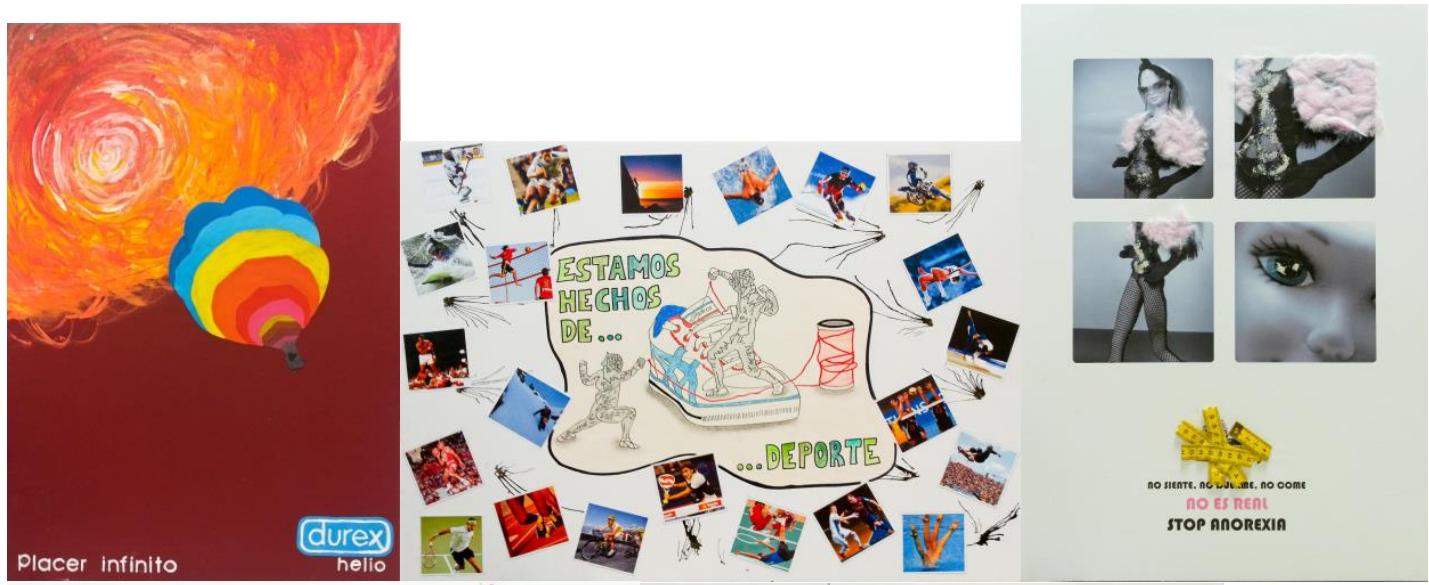

Ai ONCE
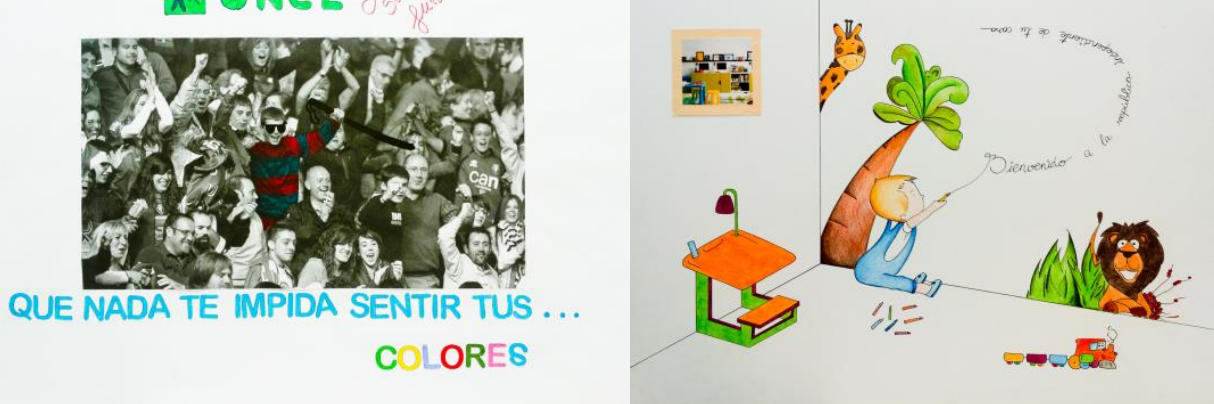


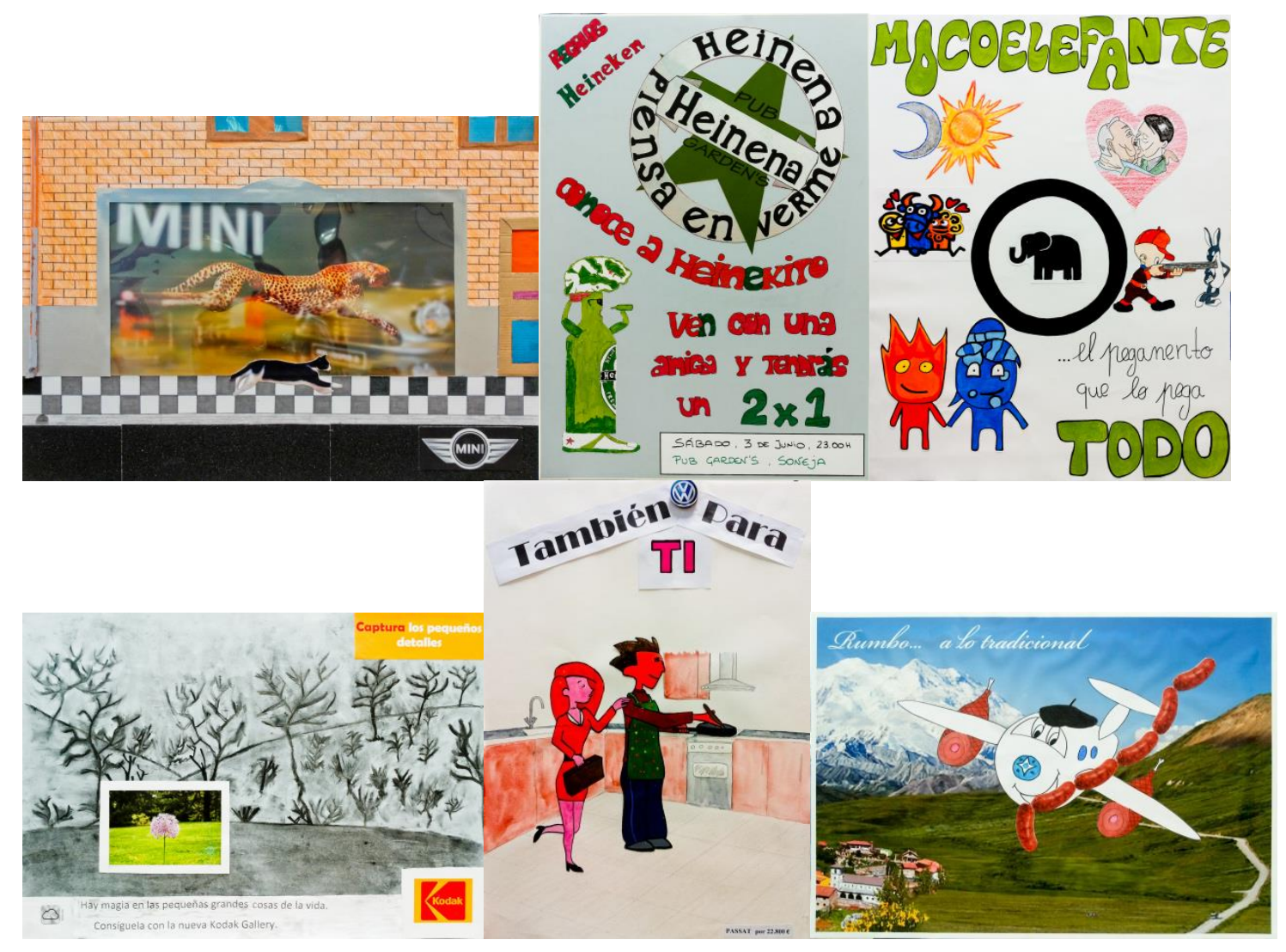

Figure 3. Designs from group B

From the results of the questionnaire given to the 10 evaluators, the mean values for novelty, style and creativity of each design are as follows (Table 1):

\begin{tabular}{|l|r|r|r|}
\hline Group A (individuals with knowledge) & \multicolumn{1}{|l|}{ Novelty } & \multicolumn{1}{l|}{ Style } & \multicolumn{1}{l|}{ CREATIVITY } \\
\hline D1 & 4.42 & 4.71 & 4.57 \\
\hline D2 & 2.66 & 3.34 & 3.00 \\
\hline D3 & 4.86 & 5.62 & 5.24 \\
\hline D4 & 3.77 & 3.91 & 3.84 \\
\hline D5 & 4.07 & 4.51 & 4.29 \\
\hline D6 & 4.04 & 3.99 & 4.02 \\
\hline D7 & 2.49 & 3.21 & 2.85 \\
\hline D8 & 3.69 & 3.17 & 3.43 \\
\hline D9 & 3.89 & 4.62 & 4.25 \\
\hline D10 & 3.51 & 3.35 & 3.43 \\
\hline D11 & 4.02 & 3.59 & 3.81 \\
\hline Group B (virtual teams without knowledge) & & & \\
\hline D1 & 3.56 & 2.85 & 3.20 \\
\hline D2 & 4.11 & 3.28 & 3.70 \\
\hline D3 & 2.97 & 2.89 & 2.93 \\
\hline D4 & 4.12 & 4.17 & 4.15 \\
\hline D5 & 5.69 & 4.25 & 4.97 \\
\hline D6 & 3.74 & 3.36 & 3.55 \\
\hline
\end{tabular}




\begin{tabular}{|l|r|r|r|}
\hline D7 & 2.41 & 3.15 & 2.78 \\
\hline D8 & 3.23 & 3.61 & 3.42 \\
\hline D9 & 4.88 & 4.64 & 4.76 \\
\hline D10 & 5.40 & 3.83 & 4.62 \\
\hline D11 & 2.81 & 3.04 & 2.93 \\
\hline
\end{tabular}

Table 1. Novelty, style and creativity values of each design

The mean values of the results of each group are shown in Table 2:

\begin{tabular}{|l|r|r|r|}
\hline & Novelty & \multicolumn{1}{|c|}{ Style } & CREATIVITY \\
\hline Group A (individuals with knowledge) & 3.76 & 4.00 & 3.88 \\
\hline Group B (virtual teams without knowledge) & 3.90 & 3.55 & 3.73 \\
\hline
\end{tabular}

Table 2. Mean values of Novelty, Style and Creativity of each group ANOVA analyses of Novelty, Style and Creativity results were performed in order to determine whether the differences between groups are significant or not. The results of the analysis can be seen on Table 3:

\begin{tabular}{|l|l|}
\hline & \\
\hline Novelty & $\mathrm{F}(1,20)=0.13 ; \mathrm{p}=0.72$ \\
\hline Style & $\mathrm{F}(1,20)=2.29 ; \mathrm{p}=0.14$ \\
\hline Creativity & $\mathrm{F}(1,20)=0.24 ; \mathrm{p}=0.63$ \\
\hline
\end{tabular}

Table 3. ANOVA analysis of Novelty, Style and Creativity comparing both groups Moreover, an study the correlation coefficient between evaluators have been performed. As it can be seen on Table 4, it has been calculated the correlation coefficient of all evaluators together, and it has been also calculated the coefficient by separating the evaluators according to their experience.

\begin{tabular}{|l|l|l|l|}
\hline & Novelty & Style & Creativity \\
\hline All evaluators & $\mathrm{r}=0.41$ & $\mathrm{r}=0.40$ & $\mathrm{r}=0.42$ \\
\hline Graphic Design & $\mathrm{r}=0.68$ & $\mathrm{r}=0.76$ & $\mathrm{r}=0.72$ \\
experts & & & \\
\hline
\end{tabular}




\begin{tabular}{|l|l|l|l|}
\hline Design Engineering & $\mathrm{r}=0.40$ & $\mathrm{r}=0.18$ & $\mathrm{r}=0.34$ \\
\hline Nonerts & & & \\
\hline
\end{tabular}

Table 4. Correlation coefficient within category of evaluator

\section{Discussion}

In a general view of the results, it can be seen from Table 2 that the style results are rated better in the work done by individuals with knowledge. This fact can suggest that the skills they have learned for representing information are not easily compensated with team-working if knowledge and practice is missing. On the other hand, the team of people without experience seems to be able to generate ideas that are not only as but even a little more novel than those of the individual working in isolation. So, together with the defended hypothesis that knowledge co-generation can enhance design creativity, this fact can also reinforce previous studies that point that teamwork increase novelty and creativity (Alves et al., 2007; González-Cruz et al., 2008). Also, previous studies demonstrated that the use or not of ICTs doesn't affect the level of creativity of the results (Chulvi et al, 2016), so this is a factor that we can discard on our research.

Nonetheless, ANOVA analyses were performed in order to determine whether the differences are significant or not. As can be seen in Table 3, none of the parameters assessed are significant, so this points to the initial hypothesis that with the virtual teamworking model, groups of individuals without specific knowledge are able to provide creative results at the same level as individuals with specific knowledge working in isolation. 
Yet, if we study the correlation coefficient between evaluators, we find that it is positive, but poor with respect to the expected values: $r=0.41$ for novelty rating; $r=$ 0.40 for style rating; and $\mathrm{r}=0.42$ for creativity rating. So, in this case, the authors decided to assess the correlation coefficient of the evaluators by their speciality, that is, by separating the ratings of the four Design Engineering experts, the four Graphic Design experts, and the two non-design experts. The results, in this case, show (as can be seen in Table 4) that the correlation coefficient of the Graphic Design experts is higher in all the aspects analysed - novelty, style and creativity - than the correlation found within other groups. Also, it can be seen that the Design Engineering experts are more accurate when rating novelty that when rating style. These results may be indicating that the claim by Besemer and O'Quin (1989) that the CPSS questionnaire can be usable by non-expert raters cannot be ensured in all cases, or at least has not turned out to be certain in this particular case.

So, the previous analysis was repeated using only the ratings of the Graphic Design experts. The new values for novelty, style and creativity for each design are shown in Table 5, and the mean values of each group are shown in Table 6.

\begin{tabular}{|l|r|r|r|}
\hline Group A (individuals with knowledge) & Novelty & Style & CREATIVITY \\
\hline D1 & 4.81 & 5.18 & 4.99 \\
\hline D2 & 3.17 & 4.12 & 3.64 \\
\hline D3 & 4.67 & 5.57 & 5.12 \\
\hline D4 & 3.50 & 3.90 & 3.70 \\
\hline D5 & 4.08 & 4.75 & 4.42 \\
\hline D6 & 4.67 & 4.65 & 4.66 \\
\hline D7 & 2.03 & 2.87 & 2.45 \\
\hline D8 & 3.75 & 3.50 & 3.63 \\
\hline D9 & 4.25 & 5.18 & 4.72 \\
\hline D10 & 3.08 & 3.13 & 3.11 \\
\hline D11 & 3.94 & 3.92 & 3.93 \\
\hline Group B (virtual teams without knowledge) & & & \\
\hline D1 & 4.39 & 2.80 & 3.59 \\
\hline D2 & 4.19 & 3.28 & 3.74 \\
\hline
\end{tabular}




\begin{tabular}{|l|l|l|r|}
\hline D3 & 2.50 & 2.42 & 2.46 \\
\hline D4 & 3.64 & 3.28 & 3.46 \\
\hline D5 & 4.92 & 3.95 & 4.43 \\
\hline D6 & 3.58 & 3.05 & 3.32 \\
\hline D8 & 2.89 & 3.15 & 3.02 \\
\hline D9 & 3.42 & 3.35 & 3.38 \\
\hline D10 & 4.94 & 4.23 & 4.59 \\
\hline D11 & 5.69 & 3.93 & 4.81 \\
\hline
\end{tabular}

Table 5. Novelty, Style and Creativity values of each design, rated only by Graphic Design experts

\begin{tabular}{|l|r|r|r|}
\hline & Novelty & Style & CREATIVITY \\
\hline Group A (individuals with knowledge) & 3.81 & 4.25 & 4.03 \\
\hline Group B (virtual teams without knowledge) & 3.91 & 3.27 & 3.59 \\
\hline
\end{tabular}

Table 6. Mean values of Novelty, Style and Creativity of each group, rated only by Graphic Design experts

With these new results it seems that the virtual teams without knowledge are able to reach the same or even a slightly better level of novelty in their designs, but they are still some distance away from achieving the same results regarding style. As can be seen in the new values of the ANOVA analysis (Table 7), when the evaluators are only experts in graphic design, the difference in style between the individuals with knowledge and the team without knowledge is significant.

\begin{tabular}{|l|l|}
\hline & \\
\hline Novelty & $\mathrm{F}(1,20)=0.06 ; \mathrm{p}=0.80$ \\
\hline Style & $\mathrm{F}(1,20)=\mathbf{9 . 4 0} ; \mathrm{p}=0.01$ \\
\hline Creativity & $\mathrm{F}(1,20)=1.68 ; \mathrm{p}=0.21$ \\
\hline
\end{tabular}

Table 7. ANOVA analysis of Novelty, Style and Creativity comparing both groups, rated only by Graphic Design experts

\section{Conclusions}

The aim of the present research was to defend the hypothesis that a large group of 
creative people organised in a VLC are able to generate a graphic design with a satisfactory level of creativity starting from an almost complete lack of knowledge about the discipline, where "satisfactory level of creativity" is understood as the level that can be achieved by an individual with specific knowledge in the subject working in isolation. For this purpose, graphic designs by the two groups were compared.

The creativity of the graphic designs was evaluated by using a questionnaire based on CPSS. The first data analysis indicates that the initial hypothesis was correct. Nonetheless, the analysis of the correlation coefficient of the evaluators (Table 3 ) shows that the conclusions may vary if we only use experts in Graphic Design as evaluators.

Thus, a parallel conclusion that was not searched for in the present research is that the postulation by Besemer and O'Quin (1989) that the CPSS questionnaire can be usable by non-expert raters cannot be ensured in all cases. New research in this aspect is therefore required in order to find out whether this research has been a particular case in which the non-accomplishment of the postulation is an exception, or if the evaluators really must be experts, despite using questionnaires based on the CPSS.

Due to the results of the correlation coefficient analysis, a new data analysis was performed by using only the assessments of the Graphic Design experts. Here, we find that the teams, despite not being experts, can offer similar levels of novelty and creativity to those of trained individuals. This is in line with previous studies which show that, when it comes to subjects with the same level of knowledge, teams foster creativity (González-Cruz et al., 2008; Thompson \& Wilson, 2015). In this case, the enhancement of creativity can be seen in the fact that inexpert teams can provide similar levels of novelty and creativity to those of individuals with knowledge working in isolation. 
Nonetheless, it has been concluded that the work done by teams without specific training display a lack of competence that prevents them from achieving the same level of graphic finish - style - as those that have previously been taught the specific competences. In other words, the specific knowledge needed to carry out the task has been proved to be essential for achieving a good rating. However, the difference seems to be perceived only by the expert eye, and not by the population in general, since when the opinion of all evaluators - experts and non-experts - were considered, the style parameter showed no significant variation between the two samples.

Hence, as a main conclusion, the hypothesis that team-working and, in this particular case, virtual team-working enhances creativity is supported up to the point that it can offset the lack of previous knowledge about how to undertake the task. But, on the other hand, at least one of the team members must be trained in the required specific competence in order to achieve a good final resolution of the work if the intention is that experts will rate the final result favourably.

\section{Acknowledgements}

The research presented in this paper was funded by the Universitat Jaume I (project ref. P1· 1B2015-30 - El arte y el diseño en la nueva sociedad digital)

\section{References}

Adell, J. \& Castañeda, L. (2012). Tecnologías emergentes, ¿pedagogías emergentes? In Hernández, J.; Pennesi, M.; Sobrino, D. y Vázquez, A. (coord.). Tendencias emergentes en educación con TIC. 13-32. Asociación Espiral, Educación y Tecnología, Barcelona. Alves, J., Marques, M. J., Saur, I., \& Marques, P. (2007). Creativity and innovation through multidisciplinary and multisectoral cooperation. Creativity and Innovation Management, 16(1), 27-34. 
Besemer S.P. \& O'Quin K. (1989), The development, reliability and validity of the revised creative product semantic scale, Creativity Research Journal, 2(4), 268-279. Chulvi, V., Mulet, E., Chakrabarti, A., López-Mesa, B. \& González-Cruz, C. (2012). Comparison of the degree of creativity in the design outcomes using different design methods. Journal of Engineering Design, 23(4), 241-269

Chulvi, V., Mulet, E., Felip, F., \& García-García, C. (2016) The effect of information and communication technologies on creativity in collaborative design. Research in Engineering Design, 1-17. Doi 10.1007/s00163-016-0227-2

Domingo, C.; Gonzalez, J. \& Lloret, O. (2008). La Web 2.0. Una revolución social y creativa. Revista Telos, 74. Fundación Telefónica, Madrid.

González-Cruz, M. C., Aguilar-Zambrano, J. A., Aguilar-Zambrano, J. J., \& Gardoni, M. (2008). TRIZ, the systematic creativity strategy used in multidisciplinary product design teams. Dyna, 83(6), 337-352.

Huerta Vásquez, E.A. (2012). Diseño incremental de e-servicios: estudio teórico, propuesta metodológica y casos prácticos. Universitat Politècnica de Catalunya. Tesis Doctoral.

Kurt, MY. (2001). The effect of a computer simulation activity versus a hands-on activity on product creativity in technology education. Journal of Technology Education. 13(1), 31-43.

Leadbeater, C. (2007). We-Think. Why mass creativity is the next big thing. URL (consulted June 2007): http://www. wethinkthebook. net/cms/site/docs/charles\% 20 full\% 20draft. pdf.

O’Quin, K. \& Besemer, S.P. (2006) Using the Creative Product Semantic Scale as a Metric for Results-Oriented Business. Creativity and Innovation Management, 15(1), $34-44$ 
Powers, M.J. (1997). How to program a virtual community. Ziff-Davis Press, New York.

Rheingold, H. (1993). The virtual community. Addison-Wesley, USA.

Sanders, E. \& Simons, G. (2009): “A Social Vision for Value Co-creation in Design”. Open Source Business Resource, December 2009.

Tainter, J., Taylor, T., Brain, R., \& Lobo, J. (2015). Emerging Trends in the Social and Behavioral Sciences: An Interdisciplinary, Searchable, and Linkable Resource.

Emerging Trends in the Social and Behavioral Sciences: An Interdisciplinary, Searchable, and Linkable Resource. 1-16. Doi 10.1002/9781118900772.etrds0326

White, A. \& Smith, B.L. (2001) Assessing advertising creativity using the Creative Product Semantic Scale. Journal of Advertising Research 41(6), 27-34. 